per cu. $\mathrm{mm}$. (in the absence of infection and bilharzial ova) in the urine obtained from the bladder by direct suprapubic puncture." In addition non-bilharzial bladder-neck obstruction is common around Kampala, in that many " apparently asymptomatic" patients (under 50 years of age) routinely attending the bougie clinic are found to have residual urine in the bladder on catheterization. Personal conversations with a colleague from Rhodesia informed me that gonococcal disease is not uncommon around Salisbury, and I see no reason why bladder-neck obstruction should not also exist there, though I am not yet prepared to publicly argue any connexion between the two conditions.

With these points in mind I would recommend that after obtaining their specimens Dr. Dukes and his colleagues would be prudent to instrument their male patients to ascertain any urethral lesion and estimate any residual urine. May I imply that perhaps some of their unselected male outpatients with unexplained high white-cell excretion rates were suffering from non-bilharzial lower genito-urinary tract disease, or even from bilharzial bladder-neck obstruction without bladder calcification or ova in the urine ?

As one of those who have been fortunate enough to experience and enjoy a period in Africa I must compliment the authors on their honesty, when after application of their rigid criteria (to which I have suggested two more) they end up with subjects who were "healthy" ! - I am, etc.,

Frenchay Hospital,

R. T. Marcus.

REFERENCE

' Marcus, R. T., E. Afr. med. Y., 1966, 43, 219

\section{Acanthosis Nigricans}

SIR,-May I add some remarks to your puzzling case of "Scleroderma with Pseudoacanthosis Nigricans" (31 December 1966, p. 1642)?

In a comprehensive analysis Dr. S. C. Gold defines pseudo-acanthosis nigricans as a " term used for the type in which there is no associated carcinoma." He then continues describing this type's reversibility and association with obesity. If Dr. Gold's first part of the definition is accepted one may give up watching for an adenocarcinoma which may take years to manifest itself. Even in the absence of a carcinoma one must occasionally have the courage to make the diagnosis of malignant acanthosis nigricans.

The woman demonstrated by the Royal Postgraduate Medical School is such a case. The dermatosis is not pseudo-acanthosis nigricans,' because she does not suffer from the conditions that usually accompany pseudo-acanthosis nigricans. She is 33 years old at the onset of the dermatosis, which is accompanied by loss of weight, vomiting, and abdominal pain. All this suggests malignant acanthosis nigricans. She dies, and no cancer is found at necropsy. There is also no evidence of acanthosis nigricans, which has disappeared. Without photographs or histological reports it is difficult for an outsider to visualize the cutaneous changes. Moreover, punctate and perifollicular pigmentation which was present on the chest and abdomen, besides apparently characteristic lesions in the axillas and body folds, is somewhat unusual for any type of acanthosis nigricans.
In summary, I would conclude that if this woman had acanthosis nigricans, which was somewhat atypical with regard to appearance and course, she most probably suffered from the malignant type. Malignant acanthosis nigricans may precede internal cancer by many years. The association of acanthosis nigricans with scleroderma in this patient seemed coincidental.-I am, etc.,

New York, Helen Ollendorff Curth.

U.S.A.

\section{Reiter's Disease}

SIR,-The report of a case of Reiter's disease treated with lincomycin hydrochloride (25 February, p. 478) is disappointing, but probably due to the fact that the authors have little personal experience of the condition. This is not surprising, not because the disease is a rarity-I see 14 or 15 cases per year-but because the presenting feature of the illness is usually urethritis and the majority of cases are seen by venereologists.

If they had read King's comprehensive account of the disease ${ }^{1}$ they would have noted that the course of Reiter's disease is such that all the features in their case which they attributed to a beneficial effect of lincomycin hydrochloride could well have occurred by chance. They would also have noted that it is impossible on the basis of the findings in a single case to say that any particular form of treatment has been beneficial, and they would have seen the effect of lincomycin hydrochloride in a number of cases before attempting to evaluate its efficacy.-I am, etc., The General Hospital,
Birmingham. W. FOWLER.

REFERENCB

1 King, A., Recent Advances in Venereology, 1964 pp. 395-466. London.

Prices and Profits in the Pharmaceutical Industry

SIR,-May I take this opportunity of correcting a statement made by Professor Henry Miller in the course of reviewing my book Prices and Profits in the Pharmaceutical Industry ${ }^{1}$ ? (25 March, p. 748). Nowhere in my book or elsewhere have I sought to defend the "pointless competitive duplication of identical products dissimilar only in name." On the contrary my point is not that duplication can be defended but, rather, that it is relatively rare. My researches suggest that there are only 1.1 brands in existence for every chemical formulation.

What I do defend, however, is " molecular manipulation," which I suggest is a totally different issue. In fact on page 92 I point out that critics have constantly confused mere product duplication with what I attempt to show is a useful and essential activity.I am, etc.,

\section{Queen's Building, MichaEL H. CoOper. The University, Exeter.}

Cooper, M. H., Prices and Profits in the PharmaCeutical.

\section{Trigeminal Neuralgia}

SIR,-A sequel of grave facial disfigurement in 12 out of 66 sufferers $(18 \%)$ treated surgically calls for comment (11 March, p. 631). Using alcohol injection, a needle entry of foramen ovale restricted to $0.5 \mathrm{~cm}$. approximately proved efficacious in the dozen or more patients I treated before the second world war. One had to be treated shortly after. None had any trophic effect.-I am, etc.,

Bristol 8.

A. WILFRID ADAMs.

\section{Driving and Social Drinking}

SIR,-There is an omission towards the end of the first paragraph of my letter published last week (1 April, p. 49). The phrase which reads 5 pints of beer should read 5 half-pints; this appears correctly in the table heading in the form $2 \frac{1}{2}$ pints.

I would also like to point out that the tables quoted, which do not precisely correspond, were used in the design of the experiment only as a guide. The B.M.A. Committee, Sir, stated quite clearly that its tables were not to be used conversely for accurate prediction. Finally, may I add that Dr. Birrell's data can be found in the Medical fournal of Australia ${ }^{1}$ ? - I am, etc., J. B. ENTICKNAP.

East Ham Mem
London E.7.

REFERENCE

1 Birrell, J., Med. F. Aust., 1965, 2, 949.

\section{Nystatin Resistance in Candida}

SIR,-I have read with interest the comments in the B.M.F. of Professor Drouhet (18 March, p. 699) and Professor H. I. Winner, Professor G. T. Stewart, and Mr. R. Holt and Dr. R. L. Newman (1 April, p. 51) on the statement by Dr. P. C. Elmes, of Belfast, in Prescribers' Fournal. ${ }^{1}$

As the manufacturers of Nystan (nystatin), we have kept a close scrutiny on the world literature relating to the activity of nystatin, and we have tried to obtain specimens from all reported cases of clinical resistance. As a result of these we can state categorically that there have been no clinical isolates of Candida (monilia, thrush) resistant to nystatin reported throughout the world, and a retraction of the statement will be published in Prescribers' fournal.

It is hoped that this retraction will clear up the confusion that has clearly arisen from the statement-a statement that was in complete contrast to all published work on sensitivity of Candida to nystatin. -I am, etc.,

BRIAN W. CROMIE, E. R. Medical Director,

REFERENCE

Elmes, P. C., Prescribers' fournal, 1966, 6, No

\section{Platelet Stickiness}

SIR,-The studies of Dr. Edwin Besterman and others on p!atelet stickiness (11 March, p. 597) are of considerable interest and importance. However, I find that some mathematical gymnastics are required to allow one to understand their results, since they express platelet stickiness as the platelet count (\%) remaining after 20 minutes rotation of the blood in the glass flask. In this they have followed the example of various other workers-that is, the higher the percentage remaining, the less is the platelet stickiness. 